\title{
INTERPRETASI HUKUM KELIMA DALAM KELUARAN 20:12 BERDASARKAN PENDEKATAN SEJARAH PENEBUSAN
}

\author{
Made Nopen Supriadi \\ Sekolah Tinggi Teologi Arastamar Bengkulu \\ madenopensupriadi@sttab.ac.id
}

\begin{abstract}
The fifth commandment is part of the Ten Commandments that God gave to Moses on Mount Sinai. The Bible is the eternal word of God, so this fifth Law has a meaning that must be understood in the infinite dimension. The Bible gives the principle that if the man fails to do one of the commandments in the Law, then he has failed. There are many interpretations of this Law, but it only comes down to practical, ethical, and moral dimensions because it solely focuses on the relevance of the present. The Bible states that the curse of the Law has been redeemed and fulfilled by Jesus Christ. After the resurrection, Jesus said that in the Torah, the Psalms and the Prophets written about Him. Thus Jesus gave a new concept of interpretation in understanding the Law. This principle is called the historical redemptive approach. The Bible states the culmination of completing all of Jesus' redemptive work is the time of the second coming in the realization of the new heaven and earth. Therefore, how to explain the relevance of the fifth Law in the context of eternity. This research focuses on the understanding of the Fifth Law in the eschatological dimension.
\end{abstract}

Keywords: The Fifth Commandments, Exodus 20:12, Historical Redemptive Approach.

\begin{abstract}
Abstrak. Perintah kelima adalah bagian dari Sepuluh Hukum Taurat yang diberikan Allah kepada Musa di gunung Sinai. Alkitab adalah Firman Allah yang kekal dengan demikian Hukum Kelima ini memiliki makna yang harus dipahami dalam dimensi kekekalan. Alkitab memberikan prinsip jika manusia gagal melakukan salah satu perintah dalam hukum Taurat, maka ia telah gagal seluruhnya. Ada banyak interpretasi terhadap hukum ini, namun hanya bermuara pada dimensi praktis, etis dan moral karena hanya befokus pada relevansi masa kini. Alkitab menyatakan bahwa kutuk Hukum Taurat telah ditebus dan digenapi oleh Yesus Kristus. Setelah kebangkitan, Yesus mengatakan bahwa dalam Kitab Taurat, Mazmur dan para Nabi tertulis tentang Dia. Dengan demikian Yesus memberikan sebuah konsep interpretasi baru dalam memahami Hukum Taurat. Prinsip inilah yang disebut dengan pendekatan sejarah penebusan (Historical Redemptive Approach). Alkitab menyatakan puncak penyempurnaan seluruh karya penebusan Yesus adalah saat kedatangan yang kedua kali dalam realisasi terhadap langit dan bumi yang baru. Oleh karena itu, bagaimanakah menjelaskan relevansi Hukum Kelima dalam konteks kekekalan. Tulisan ini fokus pada kajian terhadap pemahaman Hukum Kelima dalam dimensi esktologis.
\end{abstract}

Kata Kunci: Hukum Kelima, Keluaran 20:12, Pendekatan Sejarah Penebusan

\section{PENDAHULUAN}

Keluaran 20:1-17 adalah sungguh-sungguh peristiwa historis di mana Allah telah memberikan hukum-Nya kepada umat Israel di Gunung Sinai. Allah 
memberikan hukum agar mereka hidup dalam kasih dan kekudusan. Perintah tersebut dipahami dalam hal relasional yaitu kasih kepada Allah yang dituliskan dalam hukum pertama sampai keempat dan kasih kepada sesama manusia yang dituliskan dalam Hukum Kelima sampai kesepuluh. (Waharman 2018).

Kitab Keluaran 20 menunjukkan Allah memberikan Sepuluh Perintah kepada umat Israel (Park 2013). Salah satu perintah dalam Keluaran 20:12 berbunyi: "Hormatilah ayahmu dan ibumu, supaya lanjut umurmu di tanah yang diberikan TUHAN, Allahmu, kepadamu." Alkitab menyatakan bahwa manusia jika gagal melakukan salah-satu perintah dari semua Hukum Taurat, maka manusia itu tetap bersalah (Lih. Yak. 2:10). (Kusnandar 2017). Dengan demikian, pelaksanaan Hukum Kelima adalah sebuah keharusan dan tidak bisa dihindarkan. Roma 3:23 menyatakan bahwa semua orang telah berdosa. Lalu bagaimana solusi atas kegagalan manusia dalam melakukan hukum ke lima ini?.

Alkitab menunjukkan bahwa Hukum Kelima juga diulangi dalam kitab lain, yaitu dalam Ulangan 5:16, Matius 15:4, 19:19, Markus 7:10, 10:19, Lukas 18:20 dan Efesus 6:2. Pewahyuan Allah dari Perjanjian Lama (PL) ke Perjanjian Baru (PB) bersifat progresif. Hal tersebut mempengaruhi perkembangan makna sebuah teks. (Bruggen 2013). Karena itu perlu dikaji makna Hukum Kelima dalam setiap konteks. Allah yang memberikan hukum tersebut adalah Allah yang kekal dan Firman-Nya juga kekal (Lih. Mat. 5:18).

Dalam konsep Kristen, sejarah dunia bersifat linear dan akan mencapai puncaknya pada kedatangan Yesus Kristus yang kedua di mana akan terjadi pembaharuan atas segala ciptaan. (Pratt 2005). Lalu adakah pengaruh 
perkembangan sejarah tersebut terhadap pemahaman hukum kelima? Hal ini perlu dilakukan peninjauan untuk melihat makna hukum kelima dalam perkembangan sejarah di Alkitab secara khusus dalam sejarah penebusan. Untuk menjawab pertanyaan tersebut perlu dilakukan pengkajian makna Hukum Kelima berdasarkan pendekatan sejarah penebusan.

\section{METODOLOGI PENELITIAN}

Metodologi penelitian ini adalah deskriptif dengan studi literatus. Pendekatan yang digunakan adalah pendekatan teologis, yaitu memberikan batasan pengkajian pada perspektif teologi tertentu. Dalam hal ini penulis membatasi pemahaman dalam prinsip teologi reformed tentang sejarah penebusan. Prinsip teologis pendekatan sejarah penebusan didasarkan pada Lukas 24:27, 44 . Greidanus, yang menggunakan istilah redemptive-historical-Chrictocentris, mengatakan bahwa prinsip ini berarti mencermati bagaimana para penulis Perjanjian Baru (PB) menghubungkan tulisan-tulisan mereka dengan Perjanjian Lama (PL). Dengan begitu, panduan normatif dan terbaik untuk mengkhotbahkan Kristus dari PL adalah PB sendiri. (Greidanus 1999). Prinsip pendekatan sejarah penebusan menjelaskan sebuah teks berdasarkan prinsip perkembangan kanon teks. Oleh karena itu dalam metodologi ini akan melihat perkembangan makna teks sesuai dengan perkembangan kanon teks. (Berkhof 1984).

\section{HASIL PENELITIAN}

Hasil penelitian menunjukkan bahwa ada perkembangan makna Hukum Kelima dalam sejarah. Dalam konteks bangsa Israel, pemahaman tersebut bersifat 
progressif. Hal tersebut terlihat pada konteks Kitab Keluaran Hukum Kelima dipahami hanya sebatas aturan moral dan esklusif hanya bagi umat Israel. Pada kitab Ulangan Hukum Kelima berkembang menjadi bagian spiritualitas kehidupan yaitu kekudusan. Meskipun demikian pemahaman mereka tentang Allah sebagai Bapa belum terlihat. Daud dalam kehidupan spiritualitasnya telah memperlihatkan konsep Allah sebagai Bapa. Hal tersebut ditegaskan kembali oleh para Nabi bahwa Allah YHWH adalah Bapa.

Dalam konteks PB Tuhan Yesus mengembalikan posisi Hukum Kelima sebagai hukum moral dan spiritual yang menekankan tanggung jawab kepada Allah yang juga dinyatakan dalam tanggung jawab dalam memelihara orang tua. Yesus menolak pemberontakkan seorang anak kepada orang tua. Bahkan Ia memberikan teladan dalam melakukan Hukum Kelima dengan sempurna. Yesus menggenapi tindakan kasih baik kepada Bapa di Sorga dan juga kepada orang tua di dunia. Kesempurnaan Yesus dalam melakukan Hukum Kelima menjadi pusat penggenapan terhadap Hukum Kelima.

Penggenapan dan penebusan Yesus memberikan arti baru dalam pelaksanaan Hukum Kelima pada masa kini. Hukum ini bukanlah sebuah tuntutan, tetapi sebuah semangat atas anugerah Allah yang telah membebaskan kutuk atas kegagalan manusia dari melakukan Hukum Kelima dengan sempurna. Meskipun pelaksanaan Hukum Kelima bukan sebuah tuntutan tetapi nilai teologisnya tetap sama, karena setiap manusia yang menghormati Allah tetap juga menghormati orang tua. 
Setelah karya penebusan Yesus para Rasul juga memberikan makna yang baru terhadap Hukum Kelima. Rasul Paulus menyatakan hukum ini sebagai hukum kasih karunia dan bersifat universal kepada semua orang percaya. Bahkan Hukum Kelima menjadi sebuah tanda akhir zaman. Puncak realiasai Hukum Kelima ini pada akhirnya ialah totalitas penghormatan kepada Allah Tritunggal, yang akan terjadi secara sempurna pada langit dan bumi yang baru.

\section{PEMBAHASAN}

Hukum Kelima ini muncul pertama kali dalam Keluaran 20:12, hukum ini pertama kali diberikan oleh Allah kepada Musa di gunung Sinai. Dalam konteks Keluaran menunjukkan umat Israel baru lepas dari perbudakan. Zacharias menjelaskan arti kata hormat, yaitu bersikap santun terhadap orang tua (bd. Im. 20:9) dan bertanggung jawab memelihara kelangsungan hidup orang tua (Mat. 15:3-6, Yoh. 19:26-27). (Zacharias n.d.). Paterson, Embry dan Zucker sepakat menekankan bahwa ungkapan "hormatilah" menunjukkan bahwa orang tua diperlakukan sangat penting (Lih. Kej. 9:23, 22:1-10; 24:1-67; 45:3; 46). (Paterson 2015; Embry 2011; Zucker 2016). Cairns menekankan bahwa 'hormatilah orang tua' menyatakan 'nilailah tinggi orang tua.' Pandangan Cairns didasarkan pada Imamat 27:1-6 tentang harga pasaran untuk golongan tenaga kerja. Semakin tua umur manusia maka harganya semakin menurun, harga pekerja laki-laki untuk usia 20-60 tahun adalah 50 syikal dan harga pekerja lakilaki usia 60 tahun ke atas adalah 15 syikal. Lalu untuk tenaga kerja wanita usia 
20-60 tahun adalah 30 syikal dan harga pekerja wanita 60 tahun ke atas adalah 10 syikal. (Cairns 2015).

Philip C. Johnson menjelaskan bahwa manusia berkewajiban menghormati orang tuanya sebagaimana dia menghormati Allah dan memikul tanggungjawab atas sesamanya manusia. Kalimat "supaya lanjut umurmu" menunjukkan lamanya Israel tinggal di negeri yang dijanjikan, maupun pada usia perseorangan. (Johnson 2011). Dengan demikian dalam konteks Keluaran sikap hormat kepada orang tua dipahami sebagai refleksi dari sikap menghormati Allah. Namun pemahaman tentang umur yang panjang masih dipahami sebatas usia hidup menikmati tanah yang akan dijanjikan secara eksklusif bagi Israel. Jadi Hukum Kelima hanya menjadi aturan moral yang ketat dan eksklusif hanya kepada umat Israel. Hal tersebut terlihat dalam Imamat 20:9 yang semakin memperketat konsekuensi pelanggaran hukum ini. (Tong 2012).

Dalam Kitab Ulangan, umat Israel sedang berada di seberang sungai Yordan dan Musa kembali melakukan pengulangan pembacaan hukum Taurat. Musa dalam konteks ini kembali menegaskan hukum Taurat sebagai peringatan, ketetapan dan peraturan (Ul. 4:45). (Susanta 2019). Kline menjelaskan bahwa Israel dipanggil untuk membuat komitmen bagi pembaharuan hubungan perjanjian dengan Tuhan. Pembaharuan ini baru dilakukan setelah 40 tahun sejak hukum ini diberikan di Gunung Sinai. Menurut Kline, pengulangan pembacaan hukum ini memiliki tujuan agar umat Israel memiliki konsep bahwa hukum Taurat bukan hanya sebuah dokumen moral melainkan sebuah perjanjian. (Kline 2008). 
Dalam Ulangan 5:16 menuliskan hukum kelima dengan tambahan "...seperti yang diperintahkan kepadamu oleh Tuhan, Allahmu,..." dan "baik keadaanmu...". Penulisan tersebut adanya perbedaan penekanan hukum kelima, penekanan ini menunjukkan ketegasan hukum kelima ini adalah dari Tuhan Allah bukan hanya sekedar aturan moral. Selanjutnya ungkapan 'baik keadaanmu' dalam Kitab Ulangan dituliskan dalam beberapa kali yaitu Ulangan 4:40; 5:33; $6: 3,18 ; 10: 13 ; 12: 25,28 ; 19: 13 ; 22: 7$. Ungkapan 'baik keadaanmu' memberikan gambaran telah terjadi keadaan yang buruk kepada umat Israel, yaitu banyak generasi tua yang mati di padang gurun karena tidak menghormati kekudusan Allah dan menentang Musa sebagai orang tua ${ }^{1}$ yang ditunjuk Allah memimpin umat Israel. Selanjutnya ungkapan 'baik keadaamu' juga menunjukkan hubungan spiritualitas umat Israel kepada Allah, keadaan baik jika umat Israel melakukan apa yang telah ditetapkan Tuhan. Dengan demikian konsekuensi pelanggaran hukum kelima tidak hanya bersifat konsekuensi moral, tetapi telah menjurus kepada konsekuensi spiritual.

Pada konteks Ulangan 5:16 telah menunjukkan perkembangan makna dari Keluaran 20:12, yang awalnya hukum ini hanya bersifat moral sekarang telah memiliki penekanan aspek spiritual. Dalam Ulangan 19:3 sikap segan atau hormat kepada orang tua masuk dalam kekudusan hidup. Meskipun sikap hormat tetap dipahami hanya kepada orang tua kandung, namun nilai Hukum Kelima bersifat spiritual. Pemahaman spiritual tersebut memberikan arahan kepada anak-anak agar tetap menjaga hormat kepada orang tua. Walaupun banyak orang tua

\footnotetext{
${ }^{1}$ Usia Musa pada waktu memimpin Umat Israel adalah 80 tahun dan dalam konteks Ulangan usia Musa sudah hampir mencapai 120 tahun (Waharman 2018).
} 
memberontak kepada Allah, namun Allah menghendaki anak-anak tidak mengikuti sikap rohani yang memberontak kepada Allah. Calvin menuliskan, jika karena dosa yang dilakukan oleh orang tua, sehingga mereka tidak layak dihormati, tetaplah hormati mereka selama mereka masih hidup karena pemeliharaan Allah. (Y. Calvin 2011). Dengan demikian dalam Kitab Ulangan Hukum Kelima telah menjadi bagian spiritualitas kehidupan manusia yaitu kekudusan. Meskipun hukum tersebut masuk ke dalam bagian spiritualitas kehidupan, pemahaman umat Israel tentang Allah sebagai Bapa belum terlihat.

Perkembangan sejarah umat Israel dalam segi kepemimpinan berganti dari teokrasi menjadi monarki. Daud sebagai Raja Israel pada waktu itu telah memiliki konsep tentang Allah YHWH sebagai Bapa (Lih. Maz. 68:6; 89:26; 103:13). (Waharman 2015) . Namun dalam konteks Daud pemahaman Allah sebagai Bapa tidak diteruskan dalam memahami hukum kelima, sehingga pada era Daud dan Salomo pemahaman terhadap hukum ini masih dalam konsep moral (Ams. 1:10; $19: 26 ; 20: 20 ; 23: 22 ; 30: 17)$.

Para nabi telah menekankan bahwa Allah itu adalah Bapa yang sejati secara rohani (Lih. Yes. 9:6; 63:16; 64:8; Yer. 3:4, 19; 31:9; Mal. 1:6; 2:10). Dengan demikian pemahaman secara teologis tentang Ke-Bapaan Allah Israel sudah diterangkan oleh para nabi. Namun konteks umat Israel sebelum pembuangan dan setelah pembuangan tetap belum memaknai hukum kelima dalam keluaran 20:12 sebagai sikap hormat kepada Allah Israel sebagai Bapa. Hal tersebut dikarenakan umat Israel masih memahami hukum ini sebagai hukum moral bagi sesama manusia. (Runturambi 2019). 
Perkembangan sejarah kehidupan umat Israel memasuki zaman Perjanjian Baru. Dalam konteks Perjanjian Baru dapat dilihat pada tindakan Yesus dalam melakukan Hukum Kelima. Lukas 2:41-52 menunjukkan kisah Yesus yang tinggal di Bait Suci, Yerusalem. Yesus membuat orangtuanya cemas (ay. 48). Henry menuliskan bahwa tindakan Yesus bukanlah sikap tidak hormat kepada orang tua, melainkan Yesus mengingatkan kepada orang tuanya rahasia yang telah diketahui yaitu bahwa Dia adalah Anak Allah. (Henry 2014a). Selanjutnya sikap hormat Yesus kepada orang tua ditunjukkan pada awal mula pelayanan-Nya yaitu saat peristiwa perkawinan di Kana, Yesus mengerti perasaan ibunya (Yoh. 2:4). (Destro dan Pesce 2002). Pada waktu ibunya menyatakan bahwa "mereka kehabisan anggur" Yesus, atas kemauan sendiri, mengubah air menjadi anggur. (Scott 1988). Bahkan Yesus masih memikirkan pemeliharaan Ibunya sebelum Dia mati di kayu salib (Lih. Yoh. 19:25-27). Calvin menuliskan: "sambil menaati Allah Bapa, Kristus tidak gagal untuk melakukan kewajibannya, sebagai anak, kepada ibunya". (J. Calvin 2018, 230-31). Hal senada juga dijelaskan oleh Barclay bahwa Yesus sebagai anak tertua tidak melupakan hal-hal sepele tentang keadaan keluarganya meskipun Dia sedang menghadapi pergumulan salib. (Barclay 2001). Yesus menunjukkan karya-Nya dalam melakukan dan menggenapi Hukum Kelima dengan seimbang dan sempurna. Hal tersebut ditunjukkan melalui sikap-Nya yang tetap menghormati orang tuanya dan BapaNya di Sorga. 
Pembahasan tentang Hukum Kelima diperlihatkan Yesus dalam Matius 15:3-9. Yesus menentang pergeseran pemahaman orang Farisi dan ahli Taurat tentang Hukum Kelima. Homer A. Kent menuliskan bahwa:

Beberapa tradisi benar-benar melanggar Hukum Taurat itu sendiri. Perintah kelima (Kel. 20:12; 21:7) dilanggar dengan tipu daya tak berperasaan yaitu menyebut apa pun yang dipergunakan untuk membantu orang tua sebagai suatu persembahan kepada Allah, sehingga tidak dapat diklaim oleh pihak orang tua. (Kent 2008, 74)

Jika dilihat dari kasus tersebut, secara prinsip tidaklah salah memberikan hormat yang utama kepada Allah. Pada bagian sebelumnya Tuhan Yesus juga menyatakan dalam Matius 10:37 (bdk. Luk. 14:25-27) bahwa kasih kepada Yesus Kristus adalah kasih yang utama dibandingkan kepada keluarga, termasuk orang tua. Marshall menjelaskan inti perkataan Yesus bukan memisahkan keluarga atau mengutamakan Tuhan dengan mengabaikan keluarga. Namun dalam mengikut Yesus berkaitan erat dengan pengorbanan nyawa, bahkan ada yang harus mati karena mengikut Yesus. Kondisi demikian memisahkan mereka dari keluarga. (Marshall 1994).

Penjelasan di atas menunjukkan Yesus tidak mengajarkan pemberontakan terhadap keluarga, terutama kepada orang tua. Dalam situasi jika orang tua tidak percaya kepada Kristus dan anak menjadi percaya kepada Kristus, tetap juga tidak diperkenankan seorang anak melakukan pemberontakan kepada orang tua. Jika seorang anak percaya kepada Yesus namun orang tua belum percaya, tetapi selama anak tersebut tetap diterima di rumah, maka anak tersebut memiliki tanggung jawab memberitakan kasih Yesus kepada orang tuanya. Namun jika orang tua dengan kehendaknya mengusir atau mengancam nyawa seorang anak 
karena imannya kepada Kristus, maka seorang anak diijinkan meninggalkan orang tua karena bukan kemauannya tetapi kemauan orang tuanya dan anak tersebut bebas dari ikatan (bdg. 1Kor. 7:12-16). (Oet 2020).

Tuhan Yesus mengingatkan kembali bahwa kasih itu tertuju kepada Allah dan juga kasih itu terefleksi kepada sesama (Mat. 22:37-40). Makna hukum kasih inilah yang diterapkan Yesus dalam Matius 19:19 ketika membahas tentang Hukum Kelima. Yesus tidak menyalahkan penerapan Hukum Kelima oleh seorang muda yang kaya, meskipun orang muda tersebut menerapkan hukum dalam konsep tradisi Yahudi. (Hanson dan Oakman 1998). Namun Yesus mengoreksi motivasi anak muda tersebut karena sikapnya tidak didasarkan kasih kepada Allah. (Andrianti 2013).

Injil Yohanes menunjukkan adanya konsep Anak-anak Allah (Lih. Yoh. 1:10-13). (Supriadi dan Halawa 2018). Dalam tradisi umat Yahudi, mereka mengakui memiliki status sebagai keturunan Abraham dan mereka menghormati Abraham sebagai nenek moyang mereka. Yesus menyatakan "sebelum Abraham ada Aku telah ada" (Yoh. 8:58). (MacDonald dan Elliot 2012). Pernyataan Yesus tersebut membuka konsep baru mengenai siapakah keturunan Abraham yang sejati. Alkitab menyatakan bahwa Abraham dibenarkan karena 'percayanya' (Lih. Kej. 15:6; Rom. 4:3; Gal. 3:6, Yak, 2:23). Dengan demikian Yesus membukakan konsep bahwa Bapa yang sejati bukanlah Abraham tetapi adalah Pribadi yang diimani oleh Abraham (Lih. Yoh, 8:54). Dalam prinsip pendekatan sejarah penebusan Gerald Bray menjelaskan:

Yesus secara halus mengalihkan para lawan Yahudi-Nya dari dimensi materi ke dimensi rohani dalam pembahasan mengenai nenek moyang 
mereka.... Ia lebih bermaksud untuk mengatakan kepada mereka bahwa mereka tidak memiliki kesamaan apa pun dengan Dia dalam level rohani, sedangkan Abraham memiliki kesamaan itu. (Bray 2019, 99).

Dengan cara seperti itu Yesus memulihkan pengertian ke-Bapaan Allah yang telah diproklamirkan oleh para nabi sebelumnya. Bapa di surga berhak mendapatkan penghormatan yang tertinggi. Hal tersebut diwujudkan di dalam iman kepada Yesus Kristus, karena melalui Anak Bapa dapat dikenal. Siapa yang menghormati Anak ia juga menghormati Bapa (Yoh. 5:23; 8:19). Ini menunjukkan bahwa pada masa Tuhan Yesus posisi Hukum Kelima kembali dimengerti sebagai hukum moral dan spiritual, yang menekankan tanggung jawab kepada Allah yang juga dinyatakan dalam tanggung jawab dalam memelihara orang tua. Yesus menunjukkan sikap hormat yang sempurna kepada Bapa-Nya. (Harrisville 1969). Sikap hormat kepada orang tua adalah refleksi sikap hormat kepada Tuhan. (Gulo 2014). Tindakan Yesus dan pemahamannya mengembalikan makna asli hukum ini yaitu mengasihi Tuhan dan sesama. Kasih kepada Tuhan adalah motif utama menunjukkan kasih kepada orang tua.

Roma 3:23 menyatakan bahwa semua orang telah berdosa. Dalam pasal 2:12-13 tertulis bahwa manusia berdosa karena gagal melakukan Hukum Taurat, sebab itu manusia membutuhkan anugerah. Roma 8:3 menyatakan bahwa Allah sendiri yang melakukan Hukum Taurat melalui Yesus Kristus (bdk. Gal. 3:13). Dalam Galatia 3:23-29 dinyatakan bahwa Hukum Taurat sebagai penuntun kepada Kristus. Artinya setelah karya penebusan Kristus keselamatan manusia berpusat kepada iman yang dianugerahkan Allah (Ef. 2:8-9). (Zacharias n.d.). Sebab itu pelaksanaan Hukum Kelima pada masa kini bukanlah sebuah tuntutan hukum, 
tetapi sebuah semangat atas anugerah Allah yang telah membebaskan kutuk atas kegagalan manusia dari melakukan Hukum Kelima dengan sempurna. Meskipun begitu, nilai teologisnya tetap sama bahwa setiap manusia yang menghormati Allah tetap juga menghormati orang tua.

Efesus 6:2-3 juga kembali membahas tentang relasi anak dan orang tua dengan mengutip kembali Hukum Kelima dalam Keluaran 20:12 dan Ulangan 5:16. Konteks yang dibicarakan Paulus adalah konteks setelah karya penebusan Yesus di kayu Salib. Kolose 3:20 menunjukkan bahwa ketaatan anak kepada orang tua dalam segala hal. (Tari dan Tafonao 2019). Herbert Brichto menekankan bahwa penghormatan terhadap orang tua tidak hanya pada saat hidup tetapi juga setelah mereka mati. (Brichto 1973). Dalam Kisah Para Rasul 5:29 dan Matius 10:37 $7^{\text {a }}$ menunjukkan batasan ketaatan manusia kepada sesama manusia. Dalam Efesus 6:1 menerangkan bahwa ketaatan anak kepada orang tua 'di dalam Tuhan'. (Imeldawati 2019). Mengenai hal tersebut Calvin juga memberikan komentar bahwa batasan orang tua bertindak kepada anak dan batasan anak taat kepada orang tua, batasan itu ialah 'di dalam Tuhan'. (J. Calvin 2018).

Dalam Keluaran 20:12 dan Ulangan 5:16 terdapat istilah 'tanah yang diberikan TUHAN, Allahmu, kepadamu'. Hal tersebut jelas menunjuk kepada tanah Kanaan dan ini hanya cocok untuk orang Yahudi/Israel Saja. (Sipahutar 2019). Namun dalam prinsip pendekatan sejarah penebusan, Efesus 6:3 menggunakan istilah 'di bumi'. (Henry 2014b). Artinya berkat bagi yang menghormati orang tua tidak bersifat eksklusif hanya kepada umat Israel, tetapi juga tertuju kepada seluruh bangsa di dunia dan berkat tersebut tidak hanya 
bersifat materi (tanah kanaan) tetapi berkat tersebut sekarang bersifat rohani (lih. Ef. 6:3 "supaya kamu bahagia"). (Karman 2004). Selanjutnya apakah tanah yang diberikan Tuhan hanya bersifat rohani?. Menjawab pertanyaan tersebut Karman menuliskan:

Tema tanah dalam PL tetap diteruskan dalam PB, hanya tidak lagi spesifik menunjuk pada suatu lokasi di dunia, tetapi batas-batas wilayahnya sudah diuniversalkan. Tanah adalah tanah di mana saja, fokus PB adalah kerajaan Allah dan wujudnya sempurna dalam diri Yesus (Karman 2004, 97).

Konsep pandangan tersebut memperlihatkan perkembangan dalam sejarah penebusan, istilah "wilayahnya diuniversalkan" dan "di mana saja" menunjukkan adanya sebuah area yang tetap bereksistensi di masa yang akan datang dalam kehidupan manusia. (Vangemeren 2016). Ungkapan 'tanah yang dijanjikan' memiliki makna menunjuk kepada puncak kesempurnaan yaitu bumi dan langit yang baru (Bdk. Wahyu 21:1-3).

Dalam prinsip pendekatan sejarah penebusan, menghormati orang tua juga dijelaskan dalam cakupan dimensi eskatologis. Sikap menghormati orang tua sebagai gambaran kehidupan manusia pada akhir zaman. Ketika manusia masih menunjukkan sikap menghormati orang tua maka bahwa Tuhan masih memberkati kehidupan manusia (Lih. Mat. 24:12). Ketika kasih menjadi dingin, termasuk kasih kepada orang tua, itu adalah permulaan penderitaan tentang akhir zaman (Bdk. 2 Tim. 3:2). (BP 2006).

Puncak sejarah penebusan yang terealisasi pada kedatangan Yesus Kristus yang kedua kali. (Berkhof 2010). Pada saat itu manusia tidak lagi menjalani kehidupan secara duniawi. Allah akan melakukan pembaharuan sehingga dimensi kehidupan manusia bersifat rohani. Hukum Kelima yang diberikan Allah 
merefleksikan sikap manusia menghormati Allah yang direalisasikan kepada orang tua. Namun refleksi tersebut adalah sebuah gambaran yang menunjukkan pengormatan dalam dimensi rohani yaitu berfokus pada menghormati Bapa yang sejati, yaitu Allah Tritunggal. (Lih. Wah. 22:3-4).

\section{KESIMPULAN}

Hukum kelima adalah bagian hukum Taurat yang memberikan perintah untuk mengasihi kepada orang tua. Hukum kelima ini memberikan sebuah pendidikan moral tentang sikap menghormati yang wajib dilakukan seorang anak kepada orang tua, dan juga bagi orang muda kepada orang yang lebih tua. Alkitab memberikan perintah untuk tetap menghormati orang tua pada konteks masa kini. Penghormatan tersebut diwujudkan dengan memberikan perlakukan yang baik dan memberikan penghargaan kepada orang tua. Penghormatan terhadap orang tua pada masa kini adalah refleksi dari perwujudan penghormatan kepada Tuhan. Alkitab menerangkan orang tua tidak hanya berdasarkan pada ikatan lahiriah, tetapi juga tanpa ikatan lahiriah naik karena usia dan karena memberikan pengajaran yang benar.

Pemahaman dan penerapan hukum kelima mengalami perkembangan dari masa PL ke PB. Tuhan Yesus pada masa PB memberikan pengajaran tentang Hukum Kelima dengan tujuan meluruskan penyimpangan pelaksanaan hukum kelima. Tuhan Yesus mengajarkan agar tidak mengabaikan pemeliharaan terhadap orang tua dengan alasan melakukan Hukum Taurat yang lain. Tuhan Yesus selain memberikan pengajaran praktis, Ia juga memberikan pengajaran teologis tentang konsep ke-Bapa-an yaitu menunjuk kepada Allah yang diimani oleh Abraham. 
Hukum Kelima memiliki konsekuensi hukum yang sama dengan hukum Taurat yang lain. Kegagalan melakukan hukum kelima ini memiliki dampak serius yaitu tidak menikmati berkat tanah yang dijanjikan yaitu menunjuk kepada kehidupan di Surga. Dalam sudut pandang sejarah penebusan pribadi Tuhan Yesus telah menggenapi pelaksanaan Hukum Kelima dengan sempurna secara praktis. Yesus Kristus juga menanggung kutuk dari kegagalan umat pilihan dalam melakukan Hukum Kelima sehingga manusia dapat memperoleh berkat kehidupan kekal karena percaya kepada Yesus Kristus.

Hukum Kelima juga memiliki peranan penting untuk memberikan gambaran akhir zaman. Sikap tidak menghormati menunjukkan gambaran kehidupan akhir zaman. Puncak realisasi Hukum Kelima ini terjadi pada waktu kedatangan Tuhan Yesus kedua kali. Pada waktu orang percaya hidup dilangit dan bumi yang baru hukum kelima direalisasikan dengan memberikan penghormatan satu-satunya kepada Allah Tritunggal.

\section{DAFTAR PUSTAKA}

Andrianti, Sarah. 2013. "Yesus, Taurat Dan Budaya." Antusias: Jurnal Teologi dan Pelayanan 2 (3): 112-23.

Barclay, William. 2001. The Gospel of John. Endiburgh: Saint Andrew Press.

Berkhof, Louis. 1984. Principles of Biblical Interpretation. Grand Rapids: Baker Book House.

—. 2010. Teologi Sistematika: Doktrin Akhir Zaman. Surabaya: Momentum.

BP. 2006. "Keadaan Manusia Pada Akhir Zaman (2 Timotius 3:1-9)." SarapanPagi Biblika Ministry. 2006. http://www.sarapanpagi.org/keadaanmanusia-pada-akhir-zaman-2-timotius-3-1-9-vt1938.html.

Bray, Gerald. 2019. Allah Telah Berfirman. Surabaya: Momentum. 
Brichto, H. C. 1973. "Kin, Cult, Land and Afterlife - A Biblical Complex.” HUCA 4 (4): $27-31$.

Bruggen, Jacob van. 2013. Membaca Alkitab: Sebuah Pengantar. Surabaya: Momentum.

Cairns, I. 2015. Tafsiran Kitab Ulangan Pasal 1-11. Jakarta: BPK Gunung Mulia.

Calvin, John. 2018. Harmony of Law (Vol. 3). 3 ed. Canada: Devoted Publishing.

Calvin, Yohanes. 2011. Institutio. Jakarta: BPK Gunung Mulia.

Destro, Adriana, dan Mauro Pesce. 2002. "Between family and temple: Jesus and sacrifices." HTS Teologiese Studies / Theological Studies 58 (2). https://doi.org/10.4102/hts.v58i2.561.

Embry, Brad. 2011. "The 'Naked Narrative' from Noah to Leviticus: Reassessing Voyeurism in the Account of Noah's Nakedness in Genesis 9.22-24." Journal for the Study of the Old Testament 35 (4): 417-33. https://doi.org/10.1177/0309089210386345.

Greidanus, Sidney. 1999. Preaching Christ from the Old Testament. Grand Rapids: Eerdmans.

Gulo, Manase. 2014. "MEMBANGUN SPIRITUALITAS BERDASARKAN SURAT 1 TIMOTIUS 4:12.” Manna Rafflesia 1 (1): 36-53. https://doi.org/10.38091/man_raf.v1i1.44.

Hanson, K.C., dan Douglas E. Oakman. 1998. Palestine in the Time of Jesus: Social Structures and Social Conflicts. Minneapolis: Fortress Press. https://doi.org/10.1111/j.1467-9418.2010.00632.x.

Harrisville, R. A. 1969. "Jesus and The Family Interpretation." A Journal of Bible and Theology 23 (4).

Henry, Matthew. 2014a. Tafsiran Matthew Henry: Injil Lukas 13-24. Surabaya: Momentum.

_. 2014b. Tafsiran Matthew Henry - Kitab Efesus. Surabaya: Momentum.

Imeldawati, Tiur. 2019. "Makna Kata Taat dan Hormat dalam Efesus 6:1-3." KERUGMA: Jurnal Teologi dan Pendidikan Agama Kristen. Vol. 1. http://www.sttiimedan.ac.id/e-journal/index.php/kerugma.

Johnson, P. C. 2011. The Wycliffe Bible Commentary (Vol. 1). Diedit oleh C. F. Harrison. Malang: Gandum Mas.

Karman, Yongky. 2004. Bunga Rampai Perjanjian Lama. Jakarta: BPK Gunung 
Mulia.

Kent, H. A. 2008. The Wycliffe Bible Commentary. Malang: Gandum Mas.

Kline, M. G. 2008. The Wycliffe Bible Commentary. Diedit oleh Charles F. Pfeiffer dan Everett F. Harrison. Malang: Gandum Mas.

Kusnandar, Christie. 2017. "SEPULUH PERINTAH TUHAN BAGIAN KEDUA: KASIH TERHADAP MANUSIA DALAM TINJAUAN ETIKA KRISTEN." Jurnal Ilmiah Methonomi. Vol. 3.

MacDonald, Nathan, dan Mark W. Elliot. 2012. Genesis and Christian Theology. Grand Rapid, Michigan: Eerdmans Publishing Company.

Marshall, I. 1994. Tafsiran Alkitab Masa Kini 3 Matius - Wahyu. Jakarta: Yayasan Komunikasi Bina Kasih.

Oet, Supriadi. 2020. "TELADAN PENDERITAAN TUHAN YESUS BERDASARKAN MATIUS 27: 32-44.” Manna Rafflesia 4 (1): 57-74. https://doi.org/10.38091/man_raf.v4i1.81.

Park, Abraham. 2013. Seri 3 Sejarah Penebusan: Pelita Perjanjian Yang Tak Terpadamkan. Jakarta: Yayasan Damai Sejahterah Utama.

Paterson, R. M. 2015. Tafsiran Kitab Keluaran. Jakarta: BPK Gunung Mulia.

Pratt, Richard L. 2005. He Gave Us Stories. Surabaya: Momentum.

Runturambi, Rully Solomon. 2019. "Aspek Teologis dan Aplikatif Dasa Titah." Jurnal Teologi Berita Hidup 1 (2): 154-73. https://doi.org/ 10.38189/jtbh.v1i2.13.

Scott, Marshall S. 1988. "Honor Thy Father and Mother: Scriptural Resources for Victims of Incest and Parental Abuse." Journal of Pastoral Care 42 (2): 139-48. https://doi.org/10.1177/002234098804200205.

Sipahutar, Roy Charly. 2019. "Kajian Ekoteologis tentang Konsep tanah dalam Perjanjian Lama dan Implikasinya bagi Pemeliharaan Tanah." BIA': Jurnal Teologi dan Pendidikan Kristen Kontekstual 2 (2): 166-78. https://doi.org/10.34307/b.v2i2.95.

Supriadi, Made Nopen, dan Iman Kristina Halawa. 2018. "MAKNA PENDERITAAN KRISTUS DALAM 1 PETRUS 2:18-21.” Manna Rafflesia 5 (1): 69-91. https://doi.org/10.38091/man_raf.v5i1.99.

Susanta, Yohanes Krismantyo. 2019. "Tradisi Pendidikan Iman Anak dalam Perjanjian Lama." BIA': Jurnal Teologi dan Pendidikan Kristen Kontekstual 2 (2): 139-50. https://doi.org/10.34307/b.v2i2.127. 
Tari, Ezra, dan Talizaro Tafonao. 2019. "Pendidikan anak dalam keluarga berdasarkan kolose 3:21." Kurios: Jurnal Teologi dan Pendidikan Agama Kristen 5 (1): 24-35. https://doi.org/10.30995/kur.v5i1.93.

Tong, Stephen. 2012. "Sepuluh Hukum - Hukum Kelima (Bagian 2) - Buletin Pillar.” https://www.buletinpillar.org/. 2012. https://www.buletinpillar.org/ transkrip/sepuluh-hukum-hukum-kelima-bagian-2.

Vangemeren, Willem A.; 2016. Progres Penebusan: Kisah Keselamatan dari Penciptaan sampai Yerusalem Baru. Surabaya: Momentum.

Waharman, Waharman. 2015. "PRINSIP PENGGEMBALAAN DALAM MAZMUR 23." Manna Rafflesia 1 (2): 93-111. https://doi.org/ 10.38091/man_raf.v1i2.47.

—. 2018. "PERAN ORANG TUA DALAM PERTUMBUHAN SPIRITUALITAS ANAK: SEBUAH STUDI EKSEGETIS EFESUS 6:1-4.” Manna Rafflesia 4 (2): 116-29. https://doi.org/10.38091/man_raf.v4i2.92.

Zacharias, Ravi. n.d. "Makna menghormati orang tua [Renungan Harian]." buletinpillar.org. Diakses 20 Mei 2020. http://rec.or.id/ renungan_291_Makna-menghormati-orang-tua.

Zucker, David J. 2016. "Isaac: Sowing in Joyous Laughter, Reaping in Tears." Biblical Theology Bulletin: Journal of Bible and Culture 46 (4): 172-76. https://doi.org/10.1177/0146107916664051. 